\title{
Case Checking in Verbless Sentences Functioning as Embedded Clauses in Modern Standard Arabic: A Minimalist Account ${ }^{*}$
}

\author{
Maisoun I. Abu-Joudeh \\ Department of English Language and Literature, Hashemite University, Zarqa, Jordan
}

\begin{abstract}
The purpose of this paper is to provide an account of case checking in verbless sentences functioning as embedded clauses in Modern Standard Arabic with an eye on the recent developments within syntactic theory, namely the Minimalist Program. Using the Checking Theory as a frame of reference, I argue that the predicate in verbless sentences functioning as embedded clauses gets its accusative case under agreement with the subject. The underlying assumption is that verbless sentences are predication phrases (PredPs) dominating nominal and adjectival phrases. The PredP mediates agreement between the predicate and the subject of the verbless sentence and thus facilitates the mechanism under which case is checked. Empirical as well as crosslinguistic evidence will be given to support the proposed account.
\end{abstract}

Index Terms — minimalism, case checking, accusative

\section{INTRODUCTION}

One significant characteristic of Arabic syntax is the existence of a structure in which accusative case must be assigned to both subject and predicate of an embedded clause. The following examples are illustrative:

(1)

$$
\begin{array}{lrr}
\text { wazadtu } & \text { [Saliy-an } & \text { muxliS-an] } \\
\text { Found.1s } & \text { Ali -acc } & \text { honest-acc }
\end{array}
$$

"I found Ali sincere."

$$
\begin{array}{lll}
\text { daraitu } & \text { [al- xabar-a } & \text { Sahih-an] } \\
\text { knew.1s } & \text { the-news-acc } & \text { true-acc }
\end{array}
$$

"I found that the news is true."

$$
\begin{array}{lll}
\text { ittaxið } & \text { [aS-Sidq-a } & \text { mabda?-an }] \\
\text { take.2ms } & \text { the-sincerity-acc } & \text { principle-acc }
\end{array}
$$

(4) Let sincerity be your principle."
ittaxaða
allah-u
[ibrahi: m-a
xali: 1-an]
took.3ms
God-nom Abraham-acc
friend-acc

"And God took Abraham (for) a friend."

Each of the bracketed clauses above consists of a subject DP followed by a predicate which may consist of an adjective phrase or a noun phrase. This construction corresponds to what the Arab grammarians referred to as a verbless sentence. It is verbless because it contains no verb. A verbal sentence, in contrast, contains a verb. Compare the following illustrative examples:

$$
\begin{aligned}
& \text { a3-3aww-u 3amiil-un } \\
& \text { the-weather-nom nice-nom } \\
& \text { "The weather is nice." }
\end{aligned}
$$

$$
\begin{array}{llr}
\begin{array}{l}
\text { kaana } \\
\text { az-3aww-u } 3 \mathrm{~ms}
\end{array} \text { the weather-nom } & \begin{array}{r}
\text { 3amiil-an } \\
\text { nice-acc }
\end{array} \\
\text { "The weather was nice." } &
\end{array}
$$

The example in (6) contains a verbal copula, while (5) lacks it. This study provides an account of case checking in these constructions in which the verbless sentence is embedded under a case-assigning verb. In particular, it will investigate how the predicate in examples (1-4) gets to check its accusative case.

\section{LITERATURE REVIEW}

To the best of my knowledge, verbless sentences functioning as embedded clauses in Arabic have not received too much attention in the literature. In this section, I present how these constructions have been analyzed by Arab

\footnotetext{
"This paper is based on my Ph.D. dissertation, written under the supervision of Prof. Sara Rosen and submitted to the Department of Linguistics at the University of Kansas.
} 
grammarians.

There are three positions in the literature concerning the analysis of verbless sentences in Arabic. One analysis argues that there is a verbal copula in verbless sentences but it is not lexically realized either because it has undergone deletion (Bakir, 1980) or it is phonologically null (Fassi -Fehri, 1993). A second analysis treats verbless sentences as matrix small clauses (Mouchaweh, 1986), while a third analysis proposes that verbless sentences contain a functional projection that is marked for tense but no verbal copula (Benmamoun, 2000). I will discuss these alternatives in the following subsections

\section{A. Verbless Sentences Contain a Phonologically Null/Zero Copula}

Fassi -Fehri (1993, p.87) suggests that the copula is present at D-structure in verbless sentences but it fails to lexicalize because it carries an unmarked T feature, i.e., [-past]. In verbal sentences, in contrast, the copula bears [+past] $\mathrm{T}$ feature which forces it to be realized phonologically. Notice that the suggestion that there is a null copula in verbless sentences implies that there is a functional projection which hosts tense. That verbless sentences have an inflection structure that contains a [-past] $\mathrm{T}$ feature is borne out by the fact that temporal adverbs, depending on their temporal specification, may or may not co-occur with the tense morphology present on the verb. Consider the following examples (from Fassi-Fehri 1993, p.88):

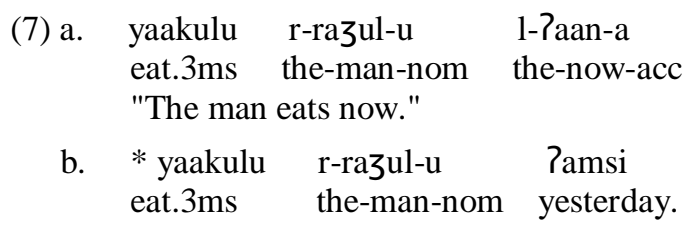

The idea here is that the temporal adverb l-Paan-a which denotes present time is compatible with the tense morphology on the verb yaakulu "eats", while Ramsi "yesterday" is not. The same contrast can be obtained in verbless sentences as the examples below show:

(8) a. r-razul-u mariiD-un 1-?aana the-man-nom sick-nom now

"The man is sick now."

b. *r-razul-u mariiD-un ?amsi

the-man-nom sick-nom yesterday

The fact that (8a) is grammatical with the temporal adverb l-Raana but not Pamsi suggests that tense is unmarked in verbless sentences. This is also supported by the fact that when the copula kaana is used in (8b), the sentence is rendered grammatical:

(9) kanna r-razul-u mariiD-an bil-?amsi

was the-man-nom sick-acc yesterday

"The man was sick yesterday."

The grammaticality of the above example is due to the compatibility of the temporal adverb and the [+past] $\mathrm{T}$ feature represented by the lexicalization of the copula.

However, Fassi- Fehri's assumption that there is a null copula in verbless sentences is not without problems. It cannot, for example, account for the fact that the predicate in a verbless sentence like (10) where the copula is without a phonological matrix is marked with nominative case while when the copula is lexicalized it (i.e., the predicate) bears accusative case. The following examples illustrate this point:

(10) az-zaww-u Zamiil-un

the-weather-nom nice-nom

"The weather is nice."

(11) kaana a3-3aww-u 3amiil-an

was. $3 \mathrm{~ms}$ the-weather-nom nice-acc

"The weather was nice."

As the above examples show, Fassi-Fehri's analysis cannot explain why when the copula is overt the predicate carries accusative case, but when it is null it carries nominative case. The same argument can be extended to the constructions under study in which both the subject and the predicate are marked as accusative.

\section{B. Verbless Sentences as Matrix Small Clauses (i.e., no an INFL Node)}

Mouchaweh (1986) (cited in Banmamoun 2000, p.39) adopts a matrix small clause analysis for Arabic verbless sentences. He claims that verbless sentences do not contain any functional projection. They only include the lexical projection of the predicate, the subject of the predicate occupying the specifier position of this projection. He posits the following D-structure for predicational sentences:

(12) 


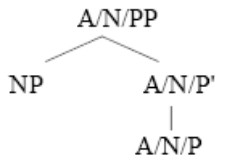

According to this analysis, there is no functional projection above the lexical projection to host tense. However, this structure cannot explain the fact that verbless sentences do sometimes contain temporal adverbs that locate the event in time, as is shown in the following example:

(13) az-3aww-u Zamiil-un ?alaan

the-weather-nom nice-nom now

"The weather is nice now."

Benmamoun (2000, p.40) argues that there are a number of good reasons why verbless sentences cannot be analyzed as small clauses. His first argument stems from the fact that a verbless sentence embedded under a tensed matrix clause does not have the same temporal reference as the matrix tense. Instead, it has its own tense interpretation. This is illustrated in (14), where the matrix clause has a past tense interpretation while the embedded verbless sentence has a present tense interpretation:

(14) qal b2lli Omar f-d-dar

say.past.3ms that Omar in-the-house

"He said that Omar is in the house."

By contrast, Small clauses depend on the matrix clause for their temporal reference, as shown in (15):

(15) $\breve{\text { S}} \partial \mathrm{f}-\mathrm{t} \quad$ Omarnå $\partial \mathrm{s}$

see.past-1s Omar sleeping

"I saw him and He was sleeping." (not "I saw him and he is sleeping.")

Another strong argument for Benmamoun's analysis of verbless sentences as full-fledged clauses that exhibit the same properties of tensed clauses is the fact that the subject surfaces with nominative case, as shown in (16):

$$
\begin{aligned}
& t-t-\text { aalib-u fii 1-maktabati } \\
& \text { the- student-nom in the-library } \\
& \text { "The student is in the library." }
\end{aligned}
$$

The fact that the subject " $t-t$ - aalib-u" is nominative can be straightforwardly explained if we assume that there is a $\mathrm{T}$ head that checks nominative case.. To account for the absence of a verbal copula in verbless sentences, Benmamoun posits that the $\mathrm{T}$ head in the present tense has different categorial feature specifications from the past and future tenses. In contrast to the past and future tenses which are specified for both $[+\mathrm{D}]$ and $[+\mathrm{V}]$ features, the present tense in verbless sentences is specified as $[+\mathrm{D}]$ only. The fact that present tense is not specified for a $[+\mathrm{V}]$ feature implies that the copula is not needed to check this feature. The $[+\mathrm{D}]$ feature, on the other hand, can be checked by the subject. Benmamoun gives the following structure for verbless sentences (Benmamoun 2000, p.49):

(17)

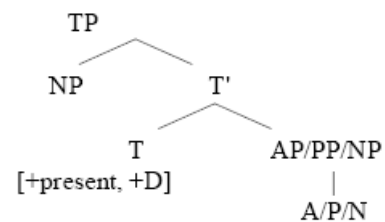

Under this analysis, the subject raises to the Spec of TP to check its [+D] feature. Since the T head is not specified for a $[+\mathrm{V}]$ feature, it does not need a verbal copula to check this feature. Therefore, verbless sentences lack a verbal copula. The past tense, in contrast, is $[+\mathrm{V}]$ and thus the presence of a verbal copula that can check the categorical $[+\mathrm{V}]$ feature is a must.

To conclude, Benmamoun proposes a theory of categorial features of tense to account for the absence of a verbal copula in verbless sentences. The main assumption of his theory is that the elements that fill the head of the TP have different categorial feature specifications (Benmamoun 2000, p.50):

(18) Present [deictic] $[+\mathrm{D}]$

$\begin{array}{ll}\text { Past } & {[+\mathrm{D},+\mathrm{V}]} \\ \text { Future } & {[+\mathrm{D},+\mathrm{V}]}\end{array}$

It follows that in both past and future tenses, a verbal copula is needed to check their [+V] feature. In present tense, there is no need for a copula since it is not specified for a $[+\mathrm{V}]$ feature.

Following Mouchaweh (1986), I assume that Arabic does have small clauses. For instance, in (1) above repeated here as (19), there is a predication relation between Saliy-an "Ali" and muxliS-an "sincere".

$$
\begin{array}{llr}
\text { wazadtu } & \text { [Saliy-an } & \text { muxliS-an] } \\
\text { found.1SG } & \text { Ali -acc } & \text { honest-acc }
\end{array}
$$

"I found Ali sincere." 
Unlike Mouchaweh, I assume that small clauses in Arabic are not bare lexical projections. This is based on the fact that predicates of small clauses agree in case with the subjects of which they are predicated even when the subjects are extracted. Consider the following sentence:

(20) Zaid-un aSlamtu-ka kariim-un

Zaid-nom told.1s-you generous-acc

Lit." I told you Zaid is generous."

I thus propose that there is a functional projection that facilitates case checking in these constructions. It provides the configuration under which predicates check their accusative case features. This issue will be discussed in detail in the next section.

To sum, none of the above proposals gives an account of the mechanism under which the predicate in Arabic embedded small clauses checks its accusative case feature. In what follows, I will provide an analysis of these constructions within the current syntactic theory. I will assume that the subject in embedded small clauses checks case by entering into a Spec-head relation with the verb of the matrix clause. The predicate, on the other hand, checks its case feature under agreement with the subject of which it is predicated.

\section{SMALl Clauses}

Most of the discussion about small clauses has been devoted to the question of whether they exist. There are two distinct traditions in the literature regarding the proper analysis of small clauses: the Small Clause Theory and the Predication Theory. The Small Clause Theory assumes that each of the bracketed strings below forms a D-structure constituent:

(21) I consider [John intelligent].

(22) I saw [John run].

(23) I consider [John my best friend].

(24) I found [John in the garden].

(Cardinaletti\& Guasti 1995, p.10)

This view has gained wide acceptance among linguists (Sportiche ,1995, Hayashi, 1991, Hornstein \& Lightfoot ,1987, Suzuki, 1991), to cite a few). A powerful empirical argument in support of the Small Clause Theory is provided by Sportiche (1995), who points out that a constituency test like coordination treats small clauses as constituents:

(25) Louis considère Marie drôle et Pierre stupide.

"Louis considers Marry funny and Bill stupid."

The strings Marie drôle and Pierre stupide are constituents since only phrasal constituents can be conjoined.

The Predication Theory, on the other hand, holds that the bracketed strings above are not clausal constituents, but the phrases consider....intelligent, saw...run, consider.....my best friend, and found....in the garden are. This assumption led Williams (1983) to posit an analysis in which the DP is directly governed by the verb and the AP serves as the predicate to that DP:

(26) I [consider [John] DP [intelligent] AP] VP

This syntactic configuration suggests that there is a subject-predicate relation established indirectly between John and intelligent. In other words, it is assumed that the complex predicate consider-intelligent is composed before the DP John is associated with the predicate intelligent and that this association is not direct. Williams (1983, p.293) presents various arguments in favor of the Predication theory. He argues, for example, that the phenomenon of scope lowering in raising constructions favors the Predication theory over the Small Clause theory. For a sentence like (27a), the SC theory assigns the structure (27b)

(27) a. someone seems sick.

b. someone ${ }_{\mathrm{i}}$ seems $\left[\mathrm{t}_{\mathrm{i}}\right.$ sick] $\mathrm{X}$

The claim is that the SC theory incorrectly predicts that a narrow scope reading can be derived from (27a):

(27c) $* x$ seems $_{\mathrm{i}}\left[\right.$ someone $_{\mathrm{i}}\left[\mathrm{t}_{\mathrm{i}}\right.$ sick $\left.] \mathrm{X}\right] \mathrm{X}$ $\neq$ There seems to be someone sick.

Under the Predication theory, (27a) has a structure like:

(27d) Someone ${ }_{\mathrm{i}}\left[\right.$ seems $\left._{0}[\text { sick }]_{A P \mathrm{i}}\right] \mathrm{VP}_{\mathrm{i}}$

Quantifier raising cannot lower the quantifier someone onto the AP because there is no trace in the AP that can function as a bound variable. Therefore, a narrow scope reading cannot be derived.

Contreras (1995) combines the two approaches in the following terms: verbal and adjectival predicates are small clauses, nominal and prepositional predicates are not. One of the facts that led Contreras to assume that adjectival and verbal predicates (i.e., predicates headed by a $[+\mathrm{V}]$ predicate) are small clauses while nominal and prepositional predicates (i.e., predicates headed by a [-V] category) are not and thus should be analyzed differently is that they differ with regard to the identification of the local domain for binding anaphors contained in them. In [+v] predicates, the local domain for an anaphor is the embedded clause containing it (p.136):

(28) a. We consider [Mary proud of herself]. b. * We consider [Mary proud of ourselves]. 
c. We consider [Mary proud of us].

d. * We consider [Mary ${ }_{i}$ proud of her $_{i}$ ].

(29) a. We saw [Mary embarrass herself].

b. * We saw [Mary embarrass ourselves].

c. We saw [Mary embarrass us].

d. * We saw [Mary ${ }_{i}$ embarrass her ${ }_{i}$ ].

$[-\mathrm{V}]$ predicates, on the other hand, show a larger governing category:

(30) a. They consider John each other i's friend.

b. They ${ }_{i}$ want the wind away from each other ${ }_{i}$.

Given these contrasts, Mary is a subject in (28) and (29) while John and the wind in (30) are not. Contreras thus concludes that nominal and prepositional predicates are structurally different from verbal and adjectival predicates. In effect, he adopts Larson's (1988) analysis of double-object constructions and proposes the structures (31) and (32) for (23) and (24), respectively (Contreras 1995, p.141):

(31)

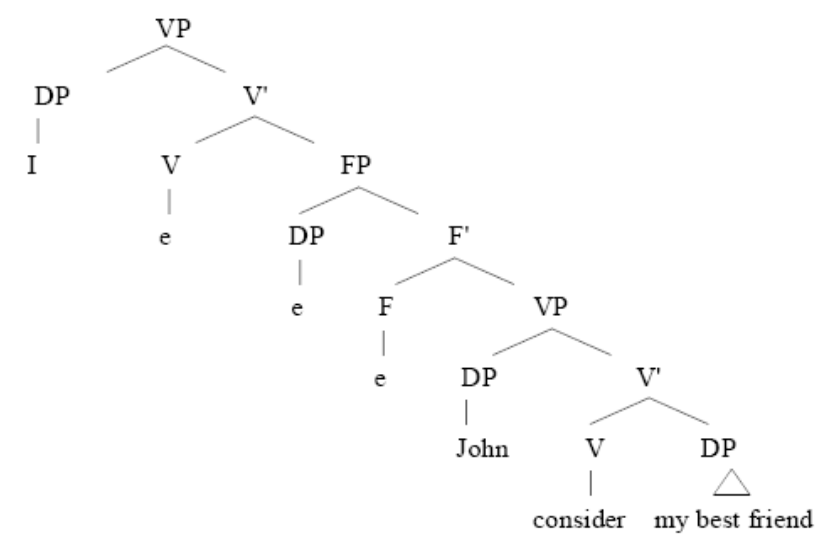

(32)

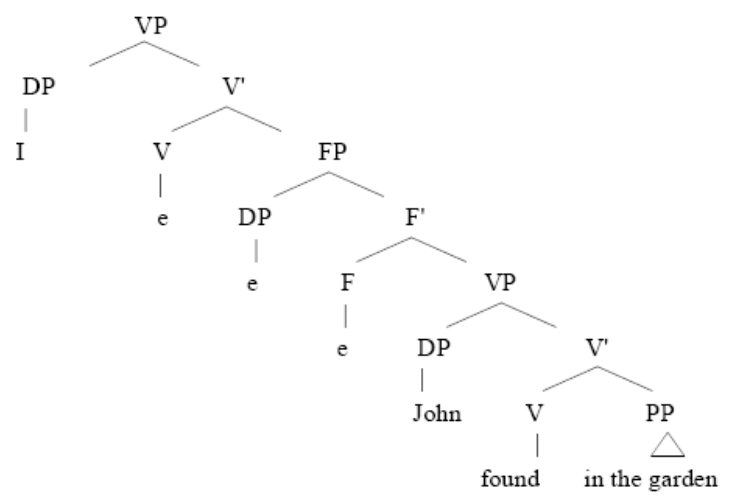

The claim is that consider and found move first to $\mathrm{F}$ and then to the higher $\mathrm{V}$ position and that John raises to Spec of FP in order to check its case features. Structures (33) and (34), on the other hand, are suggested for adjectival and verbal predicates, respectively, where the subject of the small clause raises to the Spec of FP to be assigned case by the matrix verb:

(33)

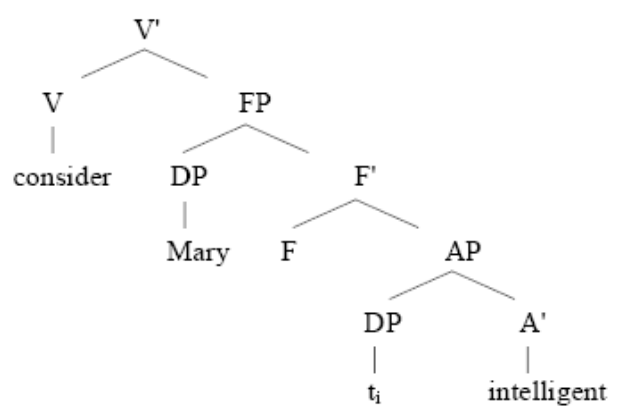

(34) 


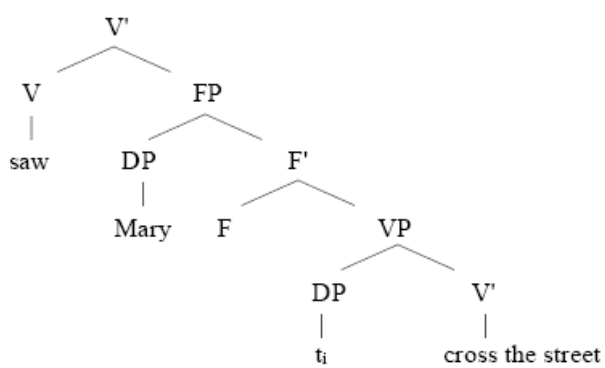

It is not clear, however, how the analysis would explain the fact that the predicate NP/AP in similar constructions in languages like Polish, Russian and Arabic are assigned accusative case. It does not provide a configuration under which these secondary predicates can check their case features. Therefore, I disagree with Contreras that adjectival and nominal predicates have different structures. I assume that there a functional projection immediately dominating the embedded AP and NP that provides the mechanism under which the predicate checks its accusative case.

To sum, if we assume the small clause theory to be correct, then what kind of syntactic category is a small clause? This question will be addressed in the next subsection.

\section{A. The Internal Structure of Small Clauses}

Among the proponents of the constituency of small clauses, there is no agreement on the precise syntactic configuration of the small clause. Two basic analyses have been proposed:

1. Small clauses as maximal projections of their predicates.

2. Small clauses as functional projections.

\section{Small Clauses as Maximal Projections}

Moro (1995), Rothstein (1995), Mouchaweh (1986) among others have argued that small clauses are lexical projections of their predicates with the subject of the predication adjoined to this projection. Moro (1995, p.112) notes that a small clause is best analyzed as an adjunction structure where a subject DP is adjoined to a maximal projection of a lexical head as in (35):

a.

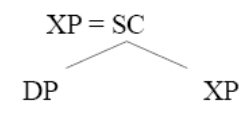

b. $\quad \mathrm{X}=\mathrm{A}, \mathrm{N}, \mathrm{V}, \mathrm{P}$

The claim is that small clauses contain a predication relation and that this relation is not established by any functional head. Moro provides a number of empirical considerations to falsify the hypothesis that the predication relation is derived by agreement (i.e., the functional head Agr) between the subject and the predicate. If a small clause is a projection of the functional head Agr, Moro argues, then two DPs mismatched in gender and number like those in (36) are expected to show agreement (Moro 1995, p.114):

(36) a. [DPques-i libr-i]

this + MASC + PL book + MASC + PL

b. [DP la caus-a della rivolta]

the $+\mathrm{FEM}+\mathrm{SG}$ cause $+\mathrm{FEM}+\mathrm{SG}$ of -riot

However, this is not the case in (37) below:

(37) Gianni ritiene [SC [DP questi libri] [DP la causa della rivolta ]].

Gianni believes these books the cause of- the riot

The two DPs in (37) above enter into a predicative relation but agreement is not realized. The fact that nominal small clauses can consist of a predication relation that is not mediated by agreement led Moro to conclude that:

"... small clauses need not necessarily be analyzed as AgrPs. They may be AgrPs, of course, as in the case of AP predicates; however, this must be regarded as an accidental fact that has nothing to do with predication but rather with specific morphological necessities of adjectives" (p.115)

Though representing a significant generalization, Moro's analysis is inadequate on conceptual grounds. Functional projections are needed to integrate the small clause within the matrix clause. As it will be argued later, they provide the configuration under which the predicate of an embedded small clause checks its case features.

Rothstein (1995) investigates the relation between small clauses and copular constructions. She argues that "be" is obligatory in both predicational and identity matrix copular sentences but optional in predicational sentences only in those cases where they are embedded under a CP (Rothstein 1995, p.41):

(38) a. I consider the winner (to be) a good runner.

$$
\text { b. I consider the winner *(to be) Mary. }
$$

Rothstein explains that be is optional in (38a) because there is a predicative relation between the subject and the predicative that licenses the structure. In contrast, in an identity sentence like (38b), neither of the two lexical constituents is a predicate. Therefore, $b e$ is obligatory to identify the Infl node which has to be affixed onto a verbal 
head. The subject NP is licensed as the subject of I' and the post- copula NP is licensed as the complement of Infl.

Under such assumptions, equative sentences do not involve a small clause because there is no way for that small clause to be licensed. Rothstein's analysis of an equative sentence gives it a structure that looks like (39):

(39)

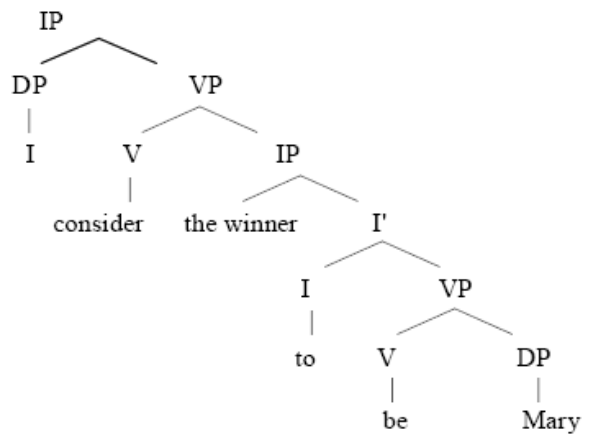

A predicative sentence, in contrast, has a structure like (40):

(40)

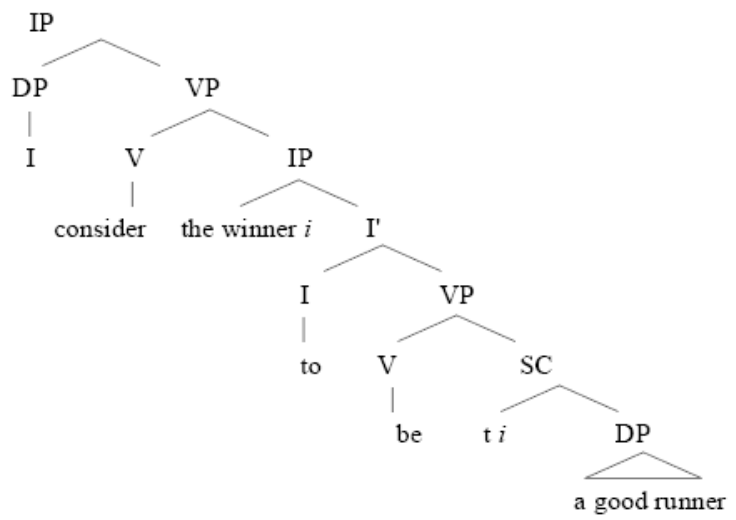

However, the above derivation does not make it clear how the predicational relation between the subject and the nonverbal predicate is licensed. This issue is tackled in the next section.

\section{Small Clauses as Functional Projections}

Guéron and Hoekstra (1995), Suzuki (1991), Nakajima (1991), Endo (1991), Kikuchi and Takahashi (1991) among others have adduced ample evidence in support of the view that small clauses are best analyzed as AgrPs. Suzuki (1991) adopts a sentence structure developed by Pollock (1989) and Chomsky (1981) as a basis for his analysis of the inner structure of small clauses. It is a structure in which Infl is split into two different heads-a T (tense) head and an Agr (agreement) head, each of which projects into a separate phrasal projection:
(41) [TP DP [T
$T[$ AgrP
Agr
VP]

He goes a step further and proposes that a subject is base-generated at the Spec of AgrP and can be raised to the Spec of TP to receive case from T. Under this view, (42) is suggested as an S-structure representation (p.28):
(42) $\quad\left[\begin{array}{cc}\text { TP } & \mathrm{DP}_{i}\left[\mathrm{~T}^{\prime}\right.\end{array}\right.$
$\mathrm{T}\left[\mathrm{AgrP} \quad \mathrm{t}_{i} \quad[\mathrm{Agr}\right.$ Agr
VP]]]]

Suzuki's hypothesis is that AgrP corresponds to an SC and thus he assumes that an SC has a representation that looks like:

(43) [AgrP DP [Agr' Agr XP]]

Suzuki presents several arguments in support of his hypothesis that an SC is Agr. One argument concerns the difference between an $\mathrm{SC}$ and other clauses with regard to propositional negation. We can see this difference in the following examples:
a. Mary can not leave
b. $-($ CAN (Mary, LEAVE) $)$
c. CAN (Mary, $\ulcorner$ (LEAVE))
a. John saw [Mary not leave].
b. John saw (NOT (LEAVE (Mary)))
c. John saw NOT-LEAVE (Mary)

(44a) can mean "Mary is allowed to stay" as in (44c) or "Mary is not allowed to leave" as in (44b). (45a) means "John saw Mary stay" as in (45c) but there is no indication that John saw someone do something else as in (45b). Suzuki argues that an SC does not allow propositional negation because it lacks a position for the negative not. This can be attributed, Suzuki (1991, p.33) states "to the categorical distinction between an SC and a finite clause, to the extent that sentential negation not lies somewhere around a tense node: a finite clause (=TP) contains T, while an SC (=Agr) does not". 
Guéron and Hoekstra (1995) propose that each lexical projection is dominated by a functional category that provides the licensing domain of the lexical projection. They also assume that each predication includes a node Agr. When a lexical head serves as a predicate, its head is checked by Agr, which itself is checked by the subject of the predication. Therefore, in a small clause such as John is foolish in (46a), the head of the small clause will be associated with Agr, yielding a structure like (46b):

(46) a. We considered John foolish.

b. [John ${ }_{\mathrm{i}}$ Agr [AP t ${ }_{\mathrm{i}}$ foolish]]

(Guéron and Hoekstra (1995, p.78)

The trace in (46b) above is motivated by Theta Theory, whereas Agr is motivated by predication. Predication is taken by Guéron and Hoekstra to be inclusion: "the subject is included in the denotation of the predicate (p.78)."

\section{B. Case Checking in Complement Small Clauses}

Chomsky (1993) suggests that the small clause complement of consider in (26) above is to be assigned the mnemonic label AgrAP:

(47) I consider [AgrAP John [AgrA' AgrA [AP intelligent]]]

The assumption is that the NP John raises further to [Spec, AgrOP] at LF where it enters into a checking relation with the matrix verb. Chomsky's (1993) analysis of small clauses as AgrPs predicts that the subject will have overt agreement with the predicate. This is based on the assumption that Agr categories mediate agreement. But if the predicate of the small clause agrees with the subject, it has case features as well. It is not clear, however, by which mechanism the case-features of the element remaining inside the small clause are checked.

Bowers (1993) proposes a universally structured theory of predication that provides a unified account of both main clause and SC predication. He hypothesizes a new functional category which he calls $\mathrm{Pr}$, a mnemonic for predication. $\operatorname{Pr}$ is assumed to have the following basic properties (Bowers 1993, p.595):

(a) The canonical D-structure position for external arguments is [Spec, Pr];

(b) $\operatorname{Pr}^{0}$ F-selects the maximal projections $\mathrm{YP}$ of any lexical category $\mathrm{Y}$;

(c) Either PrP is F-selected by $\mathrm{I}^{0}$, or it can be subcategorized as a complement by V;

(d) The semantic function of Pr is predication.

Under this assumption, predication is represented as follows:

(48)

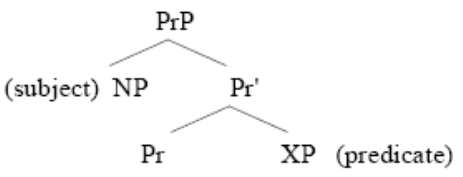

$\mathrm{X}=\{\mathrm{V}, \mathrm{A}, \mathrm{N}, \mathrm{P}\}$

Examples like (21) above can be thus represented as in (49):

(49) [IP I consider [PrP John [Pr' [Pr e][AP intelligent]]]]

With respect to structural cases like nominative and accusative, Bowers (1993) assumes that they are assigned or checked through Spec-head agreement. It follows that John enters into a Spec-head relation with V to check its accusative case, whereas the subject $I$ moves overtly from [Spec, Pr] to [Spec, IP] to check its nominative case. His analysis does not explain how the predicate gets to check its case in languages where the subject and predicate of the small clause are marked as accusative.

To sum up, various proposals have been made regarding the internal structure of small clauses. The most important conclusion that can be dawn from this heated debate about their structure is to assume that there are different types of small clauses and each type should be analyzed in a way that takes account of its properties and distribution.

\section{TOWARDS A Minimalist ACCOUNT}

In this section I present an account of case checking in verbless sentences functioning as embedded clauses. I repeat here the relevant examples:

$$
\begin{aligned}
& \text { wazadtu [Saliy-an muxliS-an] } \\
& \text { found.1s Ali -acc honest-acc } \\
& \text { "I found Ali sincere." } \\
& \text { daraitu [al- xabar-a Sahih-an] } \\
& \text { knew.1s the-news-acc true-acc }
\end{aligned}
$$

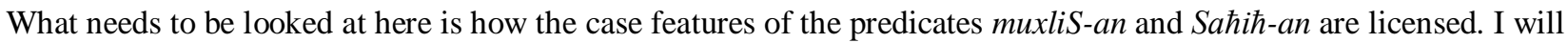
argue that these embedded clauses are predication phrases dominating an adjectival or nominal phrase. This proposal provides the configuration under which predicate NPs or APs can check their accusative case feature. Adopting the Agr-less theory of feature checking, example (51) will have the following underlying representation: 


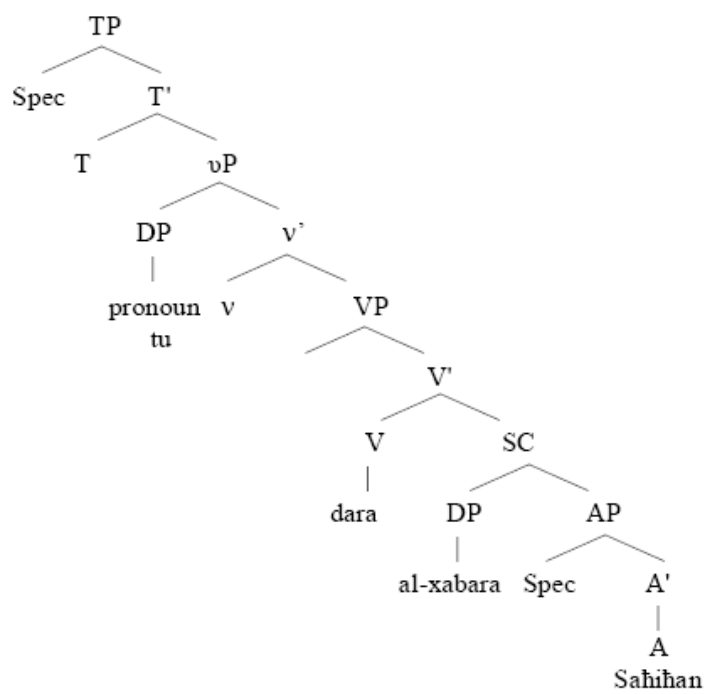

It seems that the current account faces a serious empirical problem. Since only DPs are presumed to move out of the VP for case, it is not clear how secondary predicates get their case checked. Based on the assumption that the subcategorization properties of the matrix verb require a sentence-level functional projection category to dominate the verbless sentence, I assume that there is a functional projection that mediates an agreement relation between the subject and the predicate of the verbless sentence. This is borne out by the fact that the subject and its predicate exhibit agreement in gender, number and person as is shown in the following examples:

(53) wazadtu ?at-taalib-a muztahid-an

found.1s the-student. $3 \mathrm{~ms}$-acc hard worker. $3 \mathrm{~ms}$-acc

"I found the student a hard worker."

(54) wazadtu ?at-taaliba-ta muztahida-tan

found.1s the-student.3fs-acc hard worker.3fs-acc

"I found the student a hard worker."

(55) wazadtu ?at-tulaab-a muztahid-iin

found.1s the-student.3mp-acc hard worker.3mp-acc

"I found the students hard workers."

This would be accounted for by assuming that this type of agreement is mediated by a functional projection. On these grounds, I will assume the following configuration for verbless sentences in Arabic, where PredP has agreement features (adapted from Bowers 1993):

(56)

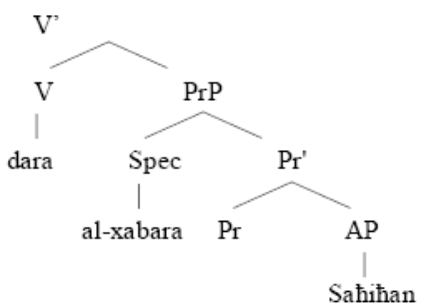

The assumption is that the case feature and the phi-features of the predicate are licensed through the trace of the subject which raises eventually to a Spec of $v \mathrm{P}$ where it can check its accusative case against that of the matrix verb

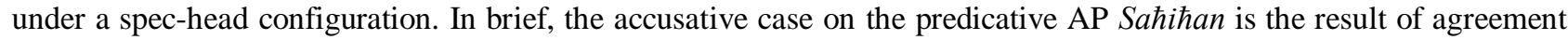
with the DP al-xabara. (57) is the LF representation of (51):

(57) 


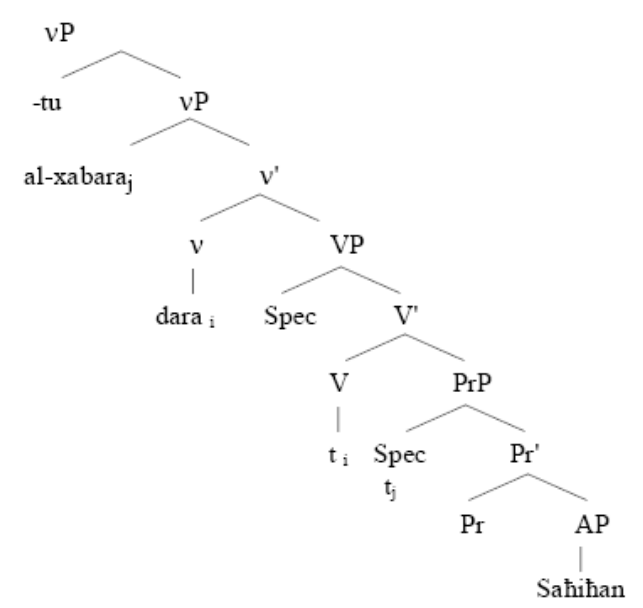

The assumption that the case of the predicate of the verbless sentence is dependant on that of the subject is based on a number of arguments. The first argument comes from the observation that negating the embedded verbless sentence causes a case shift not only on the subject of the embedded verbless sentence but also on the predicate. This is exemplified by the following constructions:

$$
\begin{aligned}
& \text { ðanantu maa Zaid-un Sadiiq-un } \\
& \text { think.1S neg Zaid-nom truthful-nom } \\
& \text { "I think that Zaid is not truthful." } \\
& \text { (From Wright 1967, p.51) }
\end{aligned}
$$

(59) Salimtu maa at-tahawwuru Sazaaßatun

know.1S neg the-hastiness-nom bravery-nom

"I know that hastiness is not bravery."

(From Hassan 1973, p.32)

As the above examples show, since the case on the predicate is the result of agreement with the subject of which it is predicated, both occur in the nominative case. Compare this to:
(60) Janantu Zaid-an Sadiiq-an
think.1s Zaid-acc truthful-acc
"I think that Zaid is truthful."

Here the negative marker ma does not occur in the embedded verbless sentence and the subject and predicate are marked as accusative. Case shift also occurs when the verbless sentence is introduced by the affirmative particle $L a$ (Wright 1976, p.51):

$$
\begin{aligned}
& \text { ðanantu la-Zaid-un } \\
& \text { think.1s qaa?im-un } \\
& \text { "I think that Zaid is standing up." }
\end{aligned}
$$

Moreover, if we assume that the case marking on the predicate of the verbless sentence stems from agreement with the subject, then once the subject is moved out of its base-generated position to a sentence-initial position and is marked as nominative, the predicate should also be marked as nominative. This prediction is borne out by the following examples:
(62) a. yaðunu a3-3 ahilu as-saraab-a maa?-an think.3ms the-ignorant-nom the-mirage-acc water-acc "The ignorant thinks he sees water but it is only a mirage."
b. as-saraab-u maa?-un yaðun a3-3 ahilu the-mirage-nom water-nom think.3ms the-ignorant-nom
c. as-saraab-u yaðun az-3 ahilu maa?-un the-mirage-nom think.3ms the-ignorant-nom water-nom

(From Hassan 1975, p.23, p. 39)

(63) a. ðanantu Zaid-an 3ahil-an think.1s Zaid-acc fool-acc "I think that Zaid is a fool."
b. Zaid-un ðanantu Zahil-un
Zaid-nom think.1s fool-nom
"Zaid; I think, is a fool."

(Wright 1976, p.51)

Examples (62a) and (63a) show that both the subject and the predicate receive accusative case from the same source, 
namely from $v$ of the verb yaðипи. However, when the subject is moved to a peripheral position, the case shifts from accusative to nominative and this affects not only the subject but the predicate of the verbless sentence as shown by (63b). This suggests that the predicte checks its case features via agreement with the subject of which it is predicated.

To sum up, the predicate of the embedded verbless sentence checks its accusative case indirectly by entering into an agreement relation with the subject which in turn checks its case against the verb of the matrix clause under a Spec-head configuration. This agreement analysis has also been adopted by Bailyn and Citko (1999) in their syntactic account of case marking of nonverbal predicates in Russian. Russian predicates exhibit two patterns of case marking: one in which the secondary predicate is marked with instrumental case and another in which the secondary predicate is marked with the same case as the NP being predicated of. (64) Shows representative examples of these two standard patterns of case marking (Bailyn and Citko 1999, p.19, p. 22):

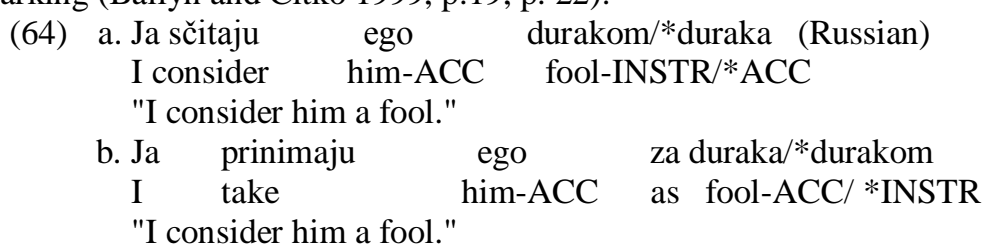

As we see in the above examples, the instrumental case appears on the DP predicate in (64a), while the secondary predicate in (64b) exhibits a different case pattern, one that is similar to the NP being predicated of, namely accusative case. Bailyn and Citko refer to the former pattern of case marking as Absolute Case and the latter as Relative Case. To account for the fact that only these two case patterns appear on predicate NPs in Russian, Bailyn and Citko (1999) adopt Bowers' (1991) PredP analysis of predication and propose that the Pred (ication) functional head has strong Instrumental Case features. This proposal is captured in the following generalizations (Bailyn and Citko 1999, p.20, p.22):

(65) Predicate Instrumental Rule Pred $^{0}$ has strong Instrumental Case

(66) Morphological Pred Rule (MPR)

Overt morphology in Pred ${ }^{0}$ absorbs Instrumental Case

According to these principles, $z a$ which is the overt realization of Pred $^{0}$ absorbs the Instrumental Case features of the Pred(ication) head. In other words, when $z a$ does not occur in the construction, the Pred ${ }^{0}$ head assigns an (inherent) Instrumental Case to its complement as is shown in (64a) above. Structure (67) below represents the configuration under which the assignment of Absolute Case (inherent Case assignment) by the Pred head takes place:

(67) Structure for Absolute Case Assignment to predicate (Bailyn and Citko 1999, p.21)

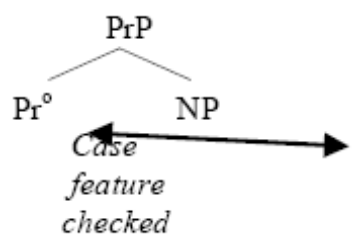

When $z a$ occurs in the construction, it absorbs the Instrumental Case features as is shown in (64b) above. The question that arises here is what happens if we treat $Z a$ as a preposition assigning accusative case. Bailyn and Citko reject traditional analyses that treat $Z a$ as a preposition and provide several arguments to support their analysis of $Z a$ as a Pred head. Their main argument is based on the observation that there are cases in Slavic where $Z a$ does not assign accusative case in predicative structures. Consider the following examples from Frank (1995, p.29):

(68) a. čto èto za kniga? what that as book-nom "What kind of book is that?"

It follows that the only way for the secondary predicate in $(64 \mathrm{~b})$ to get case is to raise to a position in which it agrees in case with the NP being predicted of. This is further illustrated by the following representation (Bailyn \& Citko 1999, p.26): 


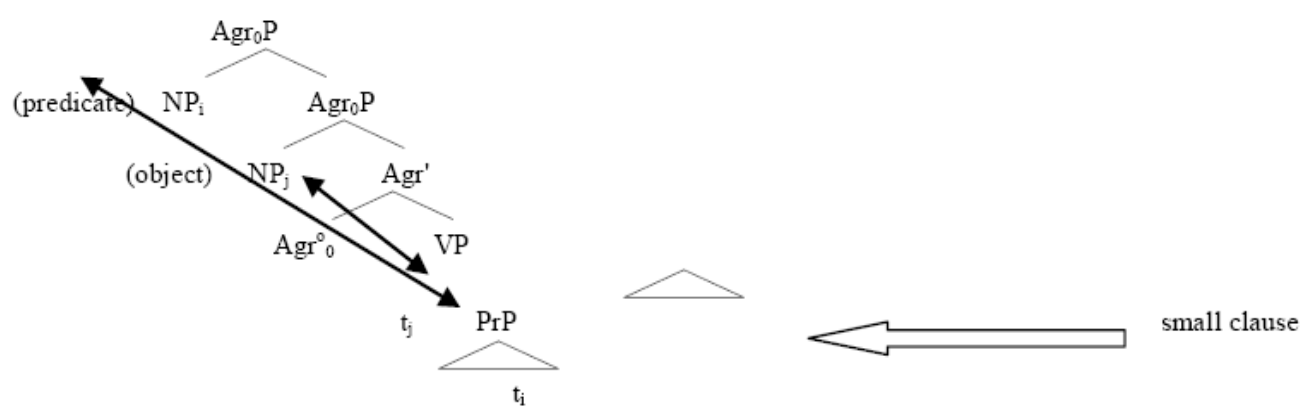

Bailyn and Citko's proposal is that structural case of predicate NPs is checked under a Spec-head configuration (AgrO in the case of accusative and AgrS in the case of nominative). It follows that in constructions where more than one element is marked with the same structural case, checking takes place in multiple Spec configurations. This is exemplified in the above representation where both the NP predicate and the NP being predicated of move to form to a multiple Spec structure. This results in having an agreeing secondary structure in which the predicate NP is marked with accusative case as the phrase being predicated of.

In the case of predicative APs, however, we find instrumental case. Consider the following example:
(70) Ja sčitaju ego glupym / *glupogo
I consider him stupid-INSTR/ *ACC
"I consider him stupid."

Bailyn and Citko argue that these APs are in fact NPs with null- $\mathrm{N}^{0}$ heads. In this respect, they act like all NPs predicates in Russian. They receive their case via the predicate instrumental rule.

To conclude, Bailyn's and Citko (1999) proposal that predicative phrases (APs and NPs) are case marked either via agreement with their antecedents or the instrumental of predication rule. Their analysis is similar to the analysis I have given for predicative phrases in Arabic. I have argued that predicative NPs and APs are predicatively case marked via agreement with their antecedent NPs. My analysis, however, differs in the sense that it does not recourse to the Agrbased theory of case to account for case checking in embedded predicative phrases.

\section{CONCLUSION}

This paper provides a minimalist account of case checking in Arabic verbless sentences functioning as embedded clauses. I have argued that the predicate of embedded verbless sentences gets its accusative case under agreement with the subject. This is based on the assumption that verbless sentences are predication phrases (PredPs) dominating nominal and adjectival phrases. The PredP mediates agreement between the predicate and the subject of the verbless sentence and thus facilitates the mechanism under which case is checked.

\section{REFERENCES}

[1] Bailyn, J.F. \& B. Citko (1999). Case and agreement in Slavic predicates .In K. Dziwirek, H. Coats \& C.M. Vakareliyska (eds.), Workshop on formal approaches to Slavic linguistics: The Seattle meeting 1998, V.44 of Michigan Slavic materials. Ann Arbor: Michigan Slavic Publications, 17-37.

[2] Bakir, M. J. (1980). Aspects of clause structure in Arabic: A study of word order variation in literary Arabic. Ph.D. dissertation, Indiana University.

[3] Benmamoun, E. (2000). The feature structure of functional categories: A comparative study of Arabic dialects. Oxford: Oxford University press.

[4] Bowers, J. (1993). The syntax of predication. Linguistic Inquiry 24.4, 591-672.

[5] Cardinaletti, A. \& M.T.Guast (1995). Small clauses: Some controversies and issues of acquisition. In Cardinaletti, A. \& M.T.Guast (eds.), 1-23.

[6] Cardinaletti, A. \& M.T. Guast (eds.) (1995). Syntax and semantics: Small clauses (vol. 28). San Diego: Academic Press. from Building (vol.20).Cambridge: The MIT Press, 1-52

[7] Chomsky, N. (1995). The minimalist program. Cambridge: The MIT Press.

[8] Chomsky, N. (2000). Minimalist inquiries. In R. Martin et. al. (eds.), Step by step: Essays on minimalist syntax in honor of Howard Lasnik. Cambridge, Mass.: The MIT Press, 89-155.

[9] Chomsky, N. (2001). Derivation by phase. In Kenstowicz, M. (ed.), Ken Hale: A life in language. Cambridge, Mass: MIT, 1-52

[10] Contreras, H. (1995). Small clauses and complex predicate. In Cardinaletti, A. \& M.T.Guast (eds.), 135-152.

[11] Endo, Y. (1991). The syntax and semantics of small clauses. In Nakajima, H. \& Tonike, Shiego (eds.),Topics in small clauses. Tokyo: Kurosio Publishers, 59- 74.

[12] Fassi-Fehri, A. (1993). Issues in the structure of Arabic clauses and words. Dordrecht: Kluwer.

[13] Frank, S. (1995). Parameters of Slavic morphosyntax. Oxford: Oxford University Press.

[14] Hornstein, N., \& D. Lightfoot (1987). Predication and PRO. Language 63, 23-52.

[15] Guéron, J. \& Hoekstra, T. (1995). The temporal interpretation of predication. In Cardenaletti, A. \& Guasti, T. (eds.), 77-107.

[16] Hassan, A. (1973). Al-naћu al-waafi. Cairo: Dar Al Marrif.

[17] Hiyashi, R. (1991). On the constituency of small clauses. In Nakajima, H. \& Tonoike, Sheigo (eds.), 11-25. 
[18] Kikuchi, A. \& Daiko Takahashi. (1991). Agreement and small clauses. In Nakajima, H. \& Tonoike, Sheigo (eds.), 75-105.

[19] Larson, R. (1988). On the double object construction. Linguistic Inquiry 19, 335-59.

[20] Moro, A. (1995). Small clauses with predicative nominals. In Cardenaletti, A. \& Guasti, T. (eds.), 109-132.

[21] Mouchaweh, L. (1986). De la syntaxe des petites prepositions. Ph.D. dissertation, Université de Paris VIII, Paris.

[22] Nakajima, H. (1991). Reduced small clauses and argumentation of AgrP. In Nakajima, H. and Tonoike, Sheigo (eds.), 39-57.

[23] Pollock, J.-Y. (1989). Verb movement, universal grammar, and the structure of IP. Linguistic Inquiry 20,365-424.

[24] Rothstein, S. (1995). Small clauses and copular constructions. In Cardenaletti, A. \& Guasti, T. (eds.), 27-48.

[25] Sportiche, D. (1995). French predicate clitics and clause structure. In Cardinaletti, A. \& Guasti, T. (eds.), 287-320.

[26] Suzuki, Y. (1991). Small clauses as AgrP*. In Nakajima, H. \& Tonoike, Sheigo (eds.), 27-37.

[27] Williams, E. S. (1983). Against small clauses. Linguistic Inquiry 14,287-308.

[28] Wright, W. (1976). A Grammar of the Arabic language. London: Cambridge University Press.

Maisoun I. Abu-Joudeh received the B.A. and M.A. degrees in English Language and Literature from the University of Jordan, Amman, Jordan, in 1995 and 1999, respectively. Her Ph.D was obtained from the University of Kansas, Kansas, USA, in 2005. She is an assistant professor in the Department of English Language and Literature at the Hashemite University. She has published in many international journals. Her current research interests include syntax, phonology, language teaching and translation. She is now teaching syntax in the Department of Language and Literature, the Hashemite University, Zarqa, Jordan. 